\title{
Study on the therapeutic effect of neural progenitor cells in mice of a glioma murine model
}

\author{
GUOZHENG XU ${ }^{1,2}$, YING LIU ${ }^{3}$, YI ZHANG ${ }^{4}$, QIAN YANG $^{4}$ and BO DIAO ${ }^{1,2}$ \\ ${ }^{1}$ Department of Neurosurgery, Wuhan General Hospital of Guangzhou Command; \\ ${ }^{2}$ Hubei Key Laboratory of Central Nervous System Tumor and Intervention; Departments of ${ }^{3}$ Clinical laboratory and \\ ${ }^{4}$ Clinical Experiment, Wuhan General Hospital of Guangzhou Command, Wuhan, Hubei 430070, P.R. China
}

Received December 11, 2015; Accepted January 28, 2016

DOI: $10.3892 / \mathrm{ol} .2016 .4158$

\begin{abstract}
Glioma is a common malignacy of the brain that affects elderly patients in particular. Despite treatment, however, the survival rate is 12 months. The aim of the present study was to examine the therapeutic effect of neural progenitor cells (NPCs) on a glioma murine model, and to determine the possible mechanism of action. A glioma murine model was constructed and the tumor volume and tumor growth rate were measured. The therapeutic effect of cell injection on the glioma mouse model mice was confirmed. The quantitative polymerase chain reaction method was used to detect the expression of proto-oncogene and tumor suppressor gene. Intracranial injection of NPCs was performed to determine cell apoptosis. Preliminary results showed the mechanism of cell therapy effect at the transcription and cellular level. Compared with the model group, the tumor volume of the mice of the cell therapy group was significantly reduced from the 6 th to 8 th week, and the tumor growth rate was downregulated. The mechanism of action identified that NPCs regulate gene expression in tumor tissues, increase the expression of tumor suppressor gene, downregulate the gene expression of tumor cells, and reverse the proto-oncogene and imbalance of gene expression in gliomas. In conclusion, the new type of cell injection method can regulate the proto-oncogene of tumor tissue and tumor suppressor gene, improve the function phenotype of the cell, and effectively improve the clinical symptoms of mice with gliomas.
\end{abstract}

\section{Introduction}

Glioma is a common malignancy of the brain, especially in middle-aged and elderly individuals, and the proportion of elderly patients is on the increase worldwide (1). Glioblastoma muhiforme patients are treated by surgery, radiotherapy and

Correspondence to: Dr Bo Diao, Department of Neurosurgery, Wuhan General Hospital of Guangzhou Command, 627 Wuluo Road, Wuhan, Hubei 430070, P.R. China

E-mail:diao_bo1@163.com

Key words: neural progenitor cell, glioma chemotherapy because of the instability of the tumor gene, the heterogeneity of the cells and extensive infiltration, and the average survival rate is approximately 12 months (2-5). Conventional radiotherapy and chemotherapy do not eliminate all tumor cells, such as glial blastoma cells through the downregulation of p53 gene and upregulation of DNA repair enzymes including 06 methylguanine DNA methyl transfer enzyme 1, to avoid the damage of chemotherapy (6-8). Thus, more effective combined therapy for patients with malignant glioma is required at the molecular level. The identification of neural stem cells (NSCs), NSCs and glioma stem cells, NSCs in the brain specific targets can gather around the glioma cell clusters and can even track single glioma cells away from glioma cell clusters (9-11). Targeting treatment of glioma with NSCs as a carrier is becoming a hot research topic. However, whether NSCs have the function to 'repair' tumor cells and have the potential to differentiate tumor is unknown.

The present study aimed to determine the therapeutic effect of neural progenitor cells (NPCs) on a mouse model of glioma, and to determine the possible mechanism of action

\section{Materials and methods}

Cell culture and drug treatment. The murine glioma cell line GL261 was obtained from American Type Culture Collection (Manassas, VA, USA). The cells were cultured in vitro in Iscove's Modified Dulbecco's Medium (Life Technologies, Grand Island, NY, USA) supplemented with $10 \%$ fetal calf serum (Sigma-Aldrich, St. Louis, MO, USA), 100 U/ml penicillin (P), and $100 \mathrm{~g} / \mathrm{ml}$ streptomycin $(\mathrm{S})(1 \% \mathrm{P} / \mathrm{S}$; Life Technologies) and $20 \mathrm{M} \beta$-mercaptoethanol (complete medium). Anti-interleukin (IL)-22 neutralising mAbs were purchased from Abcam (Cambridge, UK). mIL-22 protein was purchased from Peprotech, Inc., Rocky Hill, NJ, USA.

Animal model. Six- to 12-week-old female C57BL/6 mice were obtained from Charles River Laboratories. A brain tumor model was set up as described previously (11). A total of $1 \times 10^{4}$ GL261 glioma cells were washed twice in phosphate-buffered saline (PBS) and adjusted to $5 \mu \mathrm{l}$ of PBS in a 26-gauge Hamilton syringe (Yiliaoqixie Ltd., Shanghai, China). The mice were anesthetized with isoflurane. After shaving the scalp and making an incision, a burr hole was 


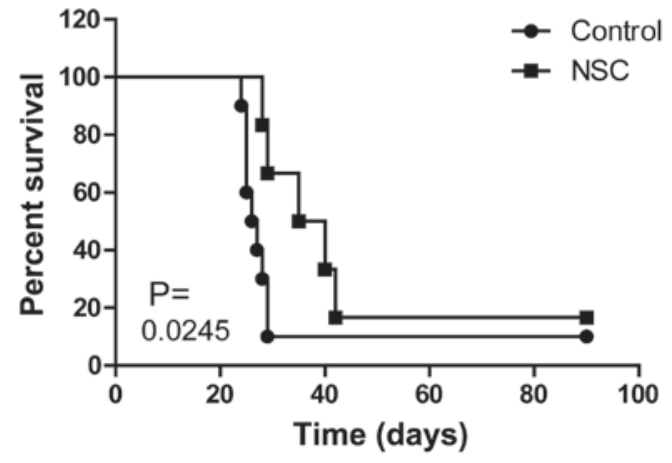

Figure 1. Therapeutic effect of neural stem cells (NSCs) on mouse model of GL261 glioma. The percentage of surviving animals over time is shown.

A

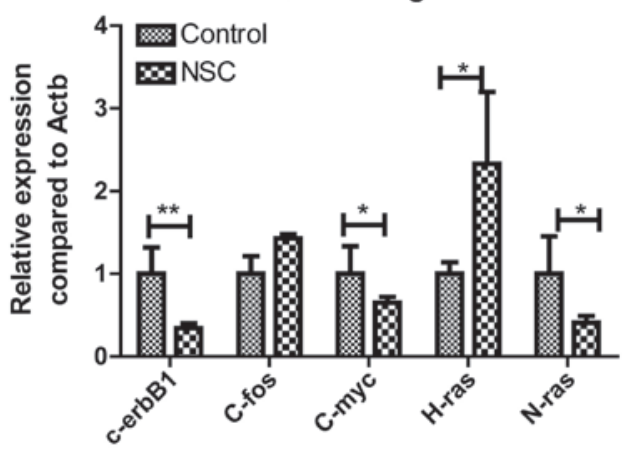

B

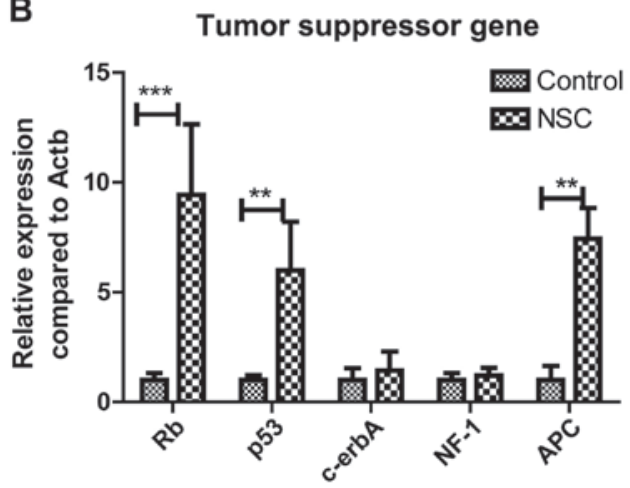

Figure 2. Effect of NPC in vitro on the gene expression of GL261 cells. (A) Relative expression of proto-oncogenes in comparison to $\beta$-actin. (B) Relative expression of tumor suppressor genes in comparison to $\beta$-actin. Neural stem cell (NSC). ${ }^{*} \mathrm{P}<0.05,{ }^{* *} \mathrm{P}<0.01$ and ${ }^{* * *} \mathrm{P}>0.05$.

made in the skull $2 \mathrm{~mm}$ lateral to the midline and $2 \mathrm{~mm}$ anterior to the bregma using a dental drill. GL261 glioma cells and $1 \times 10^{5}$ NSC cell or PBS were injected for $>1$ min at a depth of $2.5 \mathrm{~mm}$ below the dura mater into the right cerebral hemisphere. The animals were observed daily and sacrificed by cervical dislocation when characteristic symptoms such as hunched posture, reduced mobility, and significant weight loss $(20 \%)$ occurred. The mice were bred under specific pathogen-free conditions. Experimental protocols were approved by the Institutional Animal Care and Use Committee. Animals without such symptoms were regarded as long-term survivors after 90 days. The study was approved by the ethics committee of Wuhan General Hospital of Guangzhou Command.
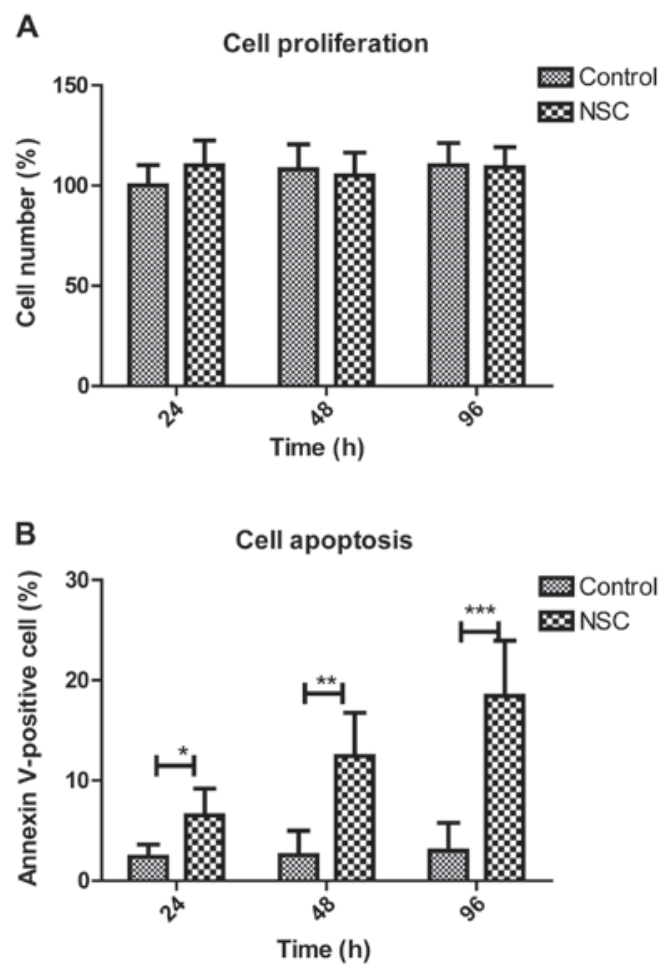

Figure 3. Effect of neural stem cell (NSC) in vitro on the phenotype of GL261 cells. (A) Cell proliferation percentage (\%) with time. (B) Cell apoptosis percentage $(\%)$ with time. ${ }^{*} \mathrm{P}<0.05,{ }^{* *} \mathrm{P}<0.01$ and ${ }^{* * *} \mathrm{P}>0.05$.

Evaluation of cell proliferation. Cells were analyzed for proliferation using a cell counting kit 8 assay (CCK-8 kit; Dojindo Molecular Technologies, Inc., Shanghai, China). The cells were seeded into 96-well plates at a density of $1 \times 10^{4}$ cells/well, and incubated in a humidified atmosphere of $5 \% \mathrm{CO}_{2}$ and $95 \%$ air overnight. Normal cell medium containing NSC or vehicle at the concentrations of $5 \mathrm{mM}$ were added. A total of $10 \mu \mathrm{l}$ CCK-8 (5 g/l in PBS) was added after $72 \mathrm{~h}$ incubation. The plates were incubated for $4 \mathrm{~h}$ and the blue dye formed was dissolved in $100 \mu$ l dimethylsulphoxide (DMSO or $\mathrm{Me}_{2} \mathrm{SO}$ ). The absorbance at $450 \mathrm{~nm}$ was recorded by ELISA (Tiangen, Beijing, China).

Evaluation of cell apoptosis. Cells were stained with annexin V (fluorescein isothiocyanate) to evaluate the cell death, according to the manufacturer's instructions (BD Biosciences, San Jose, CA, USA). Briefly, the cells were collected, washed with cold PBS and suspended in binding buffer. After staining with annexin V, the cells were analyzed using a FACScan flow cytometer (BD Biosciences).

Quantitative polymerase chain reaction ( $q P C R)$. The cells were treated with NSC in vitro and the culture period was $8 \mathrm{~h}$. Total RNA was extracted from the cells using the RNeasy mini kit (Qiagen, Beijing, China), followed by complimentary DNA synthesis using the Superscript III first strand synthesis kit (Invitrogen Life Technologies, Shanghai, China). qPCR was performed on Bio-Rad amplifier using the Bio-Rad real-time PCR mix (Bio-Rad, Berkeley, CA, USA). Data were analyzed using the threshold cycle value normalized to the endogenous reference gene. 
Statistics. Data were presented as mean \pm standard deviation. Statistical differences were determined by a two-tailed paired Student's t-test. SPSS 17.0 statistical software (SPSS, Inc., Chicago, IL, USA) was used for the analyses. $\mathrm{P}<0.05$ was considered to indicate a statistically significant difference.

\section{Results}

Therapeutic effect of NSC on mouse model of GL261 glioma. To study the effect of NSCs on the mouse glioma model, we first injected stem cells or normal saline into the brain of GL261-transplanted tumor mice. The mice of the stem cell group showed a reduction of symptoms compared with the control group, and showed that the survival time of mice was significantly prolonged and the survival rate was increased (Fig. 1). Further measurement by ELISA (13) showed that the tumor volume of mic/e of the stem cell group was significantly lower than that of the control group (Fig. 1), which supported the data of the survival rate.

Effect of NSC in vitro on gene expression of GL261 cells. In order to elucidate the mechanism of NSCs, the cells were co-cultured with GL261 cells at aratio of 1:1 to detect the expression of proto-oncogene and tumor suppressor gene. It was found that NSCs inhibited the expression of c-erbB1/ C-myc/N-ras, but promoted the expression of tumor suppressor genes $R b, p 53, A P C$. Overall, NSCs can regulate the balance of the proto-oncogene/tumor suppressor gene of GL261 glioma cells, thereby effectively improving the symptoms of glioma (Fig. 2A and B).

Effect of NSC in vitro on the phenotype of GL261 cells. The results showed that compared with the control group, the NSC treatment group inhibited the proliferation of GL261 cells as well inhibition to cell apoptosis, in a time-dependent manner. The results suggested that NSC cells can mediate the apoptotic phenotype of GL261 cells by regulating the expression of oncogenes and tumor suppressor genes, and the mechanism of NSC in vivo was preliminarily elucidated (Fig. 3A and B).

\section{Discussion}

Glioma is a common malignant tumor of the brain that affects primarily elderly individuals (14). The occurrence and development of many tumors including gliomas is associated with the imbalance of gene expression, e.g., proto-oncogene and tumor suppressor gene. In healthy conditions, the two genes are in a state of equilibrium. However, once there is imbalance the expression of proto-oncogenes are upregulated and the tumor suppressor genes are downregulated, leadimg to development of the tumor eventually (15-17).

In the present study, mouse glioma 261 (G1261) cells are used frequently in experimental glioblastoma therapy. However, no detailed description of the Gl261 tumor model is available. In the present study, Gl261 cells carried point mutations in the K-ras and p53 genes. Basal major histocompatibility complex (MHC) I, but not MHCII, expression was detected in G1261 cells. The introduction of interferon$\gamma$-encoding genes increased the expression of both MHCI and MHCII (13). The results of the present study showed that the cells directly regulated transcription of the tumor genes. Glioma stem cells and NSCs do not have a dependent relationship, and there are even mutual constraints. Suzuki et al (18) found that the cell factor secreted by the nerve bulb, which is obtained by subculture can inhibit the proliferation of glioma cells. In vitro, their results showed that molecules with a weight between 50,000 and 100,000 have a role in inhibiting tumor activity. Additionally, following implantation of $203 \mathrm{G}$ glioma cells and neural progenitor cells in the cerebellar medulla pool, the survival time of mice in the combination group was significantly prolonged (18). In addition, transforming growth factor- $\beta$ secreted by NSCs has an inhibitory effect on glioma (19). Proto-oncogene is a gene that is associated with cell proliferation, and is necessary to maintain normal life activity with high conservatism in evolution. When the structure or regulatory region of the proto-oncogene is altered, the gene products increase or the activity of the gene is strengthened, causing the cell to proliferate and form a tumor. The findings of the current study have shown that NSC regulates the original gene, but does not affect cell proliferation, indicating that NSC has other regulatory pathways. Tumor occurrence is the result of the synergistic action of multiple proto-oncogenes and tumor suppressor genes.

Orian et al (20) detected the co-expression of e-erbBI, $\mathrm{C}$-mye, $\mathrm{Ha} / \mathrm{N}$-ras and $\mathrm{C}$-fos genes and found that the number of cancer genes was associated with tumor. There were two types of gene co-expression in the improved grade of the tumor. However, but there were 3 or 4 types of co-expression of cancer genes in the variant star tumor and glioblastoma cell tumor. The co-expression of c-erbBI/Ha/N-ras/C-fos is the most common in the variant star tumor, while the co-expression of c-erbBI/C-myc/Ha/N-ras was found to be the most common in glioblastoma, with the latter being found to have four co-expressions of oncogenes. Previous findings have shown that C-erbB1 gene amplification was accompanied with the amplification of C-myc and/or C-fos gene (21), suggesting that the epidermal growth factor receptor and C-515 encoding platelet derived growth factor can lead to growth of the expression level of the $C$-myc and $C$-fos genes. The p53, p6z, pZI'ip and growth factor receptors often co-regulate the cell proliferation cycle (22). In glioma cells, growth factor receptor and P53 gene mutation were overexpressed the mutant p53 protein inhibited the expression of $\mathrm{p} 21 \mathrm{c} \cdot \mathrm{Pl}$, while leading to the negative regulation of p21dPI on the cyclin-dependent kinase being decreased. Thus, the above factors accelerated the cells from $\mathrm{G}$ to $\mathrm{S}$ stage. Previous studies have indicated that the occurrence of glioma is the result of many cancer and tumor suppressor genes. Of these, c-erbBI, C-myc, Ha/N-ras, $\mathrm{C}$-fos and p53 genes have cleared roles, although their interaction mechanism remains to be further determined $(23,24)$. In conclusion, NSC cell transplantation can effectively improve MCF-7 breast cancer model in mice through the dual regulation of the proto-oncogene/suppressor of tumor cells, and a potentially effective method for treating breast cancer.

\section{Acknowledgements}

The present study was supported by the Medical Scientific Research Foundation of Hubei Province, China (no. WJ2015MB118). 


\section{References}

1. Goodenberger ML and Jenkins RB: Genetics of adult glioma. Cancer Genet 205: 613-621, 2012.

2. Buck JR, McKinley ET, Fu A, Abel TW, Thompson RC, Chambless L, Watchmaker JM, Harty JP, Cooper MK and Manning HC: Preclinical TSPO Ligand PET to Visualize Human Glioma Xenotransplants: A Preliminary Study. PLoS One 10: e0141659, 2015.

3. Codo P, Weller M, Meister G, Szabo E, Steinle A, Wolter M, Reifenberger G and Roth P: MicroRNA-mediated down-regulation of NKG2D ligands contributes to glioma immune escape. Oncotarget 5: 7651-7662, 2014.

4. Breunig JJ, Levy R, Antonuk CD, Molina J, Dutra-Clarke M, Park H, Akhtar AA, Kim GB, Hu X, Bannykh SI, et al: Ets factors regulate neural stem cell depletion and gliogenesis in Ras Pathway Glioma. Cell Reports 12: 258-271, 2015.

5. Boisselier B, Gállego Pérez-Larraya J, Rossetto M, Labussière M, Ciccarino P, Marie Y, Delattre JY and Sanson M: Detection of IDH1 mutation in the plasma of patients with glioma. Neurology 79: 1693-1698, 2012.

6. Blough MD, Beauchamp DC, Westgate MR, Kelly JJ and Cairncross JG: Effect of aberrant p53 function on temozolomide sensitivity of glioma cell lines and brain tumor initiating cells from glioblastoma. J Neurooncol 102: 1-7, 2011.

7. Lalezari S, Chou AP, Tran A, Solis OE, Khanlou N, Chen W, Li S, Carrillo JA, Chowdhury R, Selfridge J, et al: Combined analysis of O6-methylguanine-DNA methyltransferase protein expression and promoter methylation provides optimized prognostication of glioblastoma outcome. Neuro-oncol 15: 370-381, 2013.

8. Parkinson JF, Wheeler HR, Clarkson A, McKenzie CA, Biggs MT, Little NS, Cook RJ, Messina M, Robinson BG and McDonald KL: Variation of O(6)-methylguanine-DNA methyltransferase (MGMT) promoter methylation in serial samples in glioblastoma. J Neurooncol 87: 71-78, 2008.

9. Aboody KS, Brown A, Rainov NG, Bower KA, Liu S, Yang W, Small JE, Herrlinger U, Ourednik V, Black PM, et al: Neural stem cells display extensive tropism for pathology in adult brain: Evidence from intracranial gliomas. Proc Natl Acad Sci USA 97: 12846-12851, 2000

10. BaramiK:Relationshipofneuralstemcellswiththeirvascular niche: implications in the malignant progression of gliomas. J Clin Neurosci 15: 1193-1197, 2008.

11. Sanai N, Alvarez-Buylla A and Berger MS: Neural stem cells and the origin of gliomas. N Engl J Med 353: 811-822, 2005.

12. Grauer OM, Molling JW, Bennink E, Toonen LW, Sutmuller RP, Nierkens S and Adema GJ: TLR ligands in the local treatment of established intracerebral murine gliomas. J Immunol 181: 6720-6729, 2008.

13. Szatmári T, Lumniczky K, Désaknai S, Trajcevski S, Hídvégi EJ, Hamada $\mathrm{H}$ and Sáfrány G: Detailed characterization of the mouse glioma 261 tumor model for experimental glioblastoma therapy. Cancer Sci 97: 546-553, 2006.
14. Ostrom QT, Bauchet L, Davis FG, Deltour I, Fisher JL, Langer CE, Pekmezci M, Schwartzbaum JA, Turner MC, Walsh KM, Wrensch MR and Barnholtz-Sloan JS: The epidemiology of glioma in adults: a 'state of the science' review. Neuro-Oncol 16: 899-913, 2014.

15. Lee SG, Kim K, Kegelman TP, Dash R, Das SK, Choi JK, Emdad L, Howlett EL, Jeon HY, Su ZZ, et al: Oncogene AEG-1 promotes glioma-induced neurodegeneration by increasing glutamate excitotoxicity. Cancer Res 71: 6514-6523, 2011.

16. Sano M, Genkai N, Yajima N, Tsuchiya N, Homma J, Tanaka R, Miki T and Yamanaka R: Expression level of ECT2 proto-oncogene correlates with prognosis in glioma patients. Oncol Rep 16: 1093-1098, 2006.

17. ten Haaf A, Bektas N, von Serenyi S, Losen I, Arweiler EC, Hartmann A, Knüchel R and Dahl E: Expression of the glioma-associated oncogene homolog (GLI) 1 in human breast cancer is associated with unfavourable overall survival. BMC Cancer 9: 298, 2009.

18. Suzuki T, Izumoto S, Wada K, Fujimoto Y, Maruno M, Yamasaki M, Kanemura Y, Shimazaki T, Okano $\mathrm{H}$ and Yoshimine T: Inhibition of glioma cell proliferation by neural stem cell factor. J Neurooncol 74: 233-239, 2005.

19. Tran TT, Uhl M, Ma JY, Janssen L, Sriram V, Aulwurm S, Kerr I, Lam A, Webb HK, Kapoun AM, et al: Inhibiting TGF-beta signaling restores immune surveillance in the SMA-560 glioma model. Neuro-oncol 9: 259-270, 2007.

20. Orian JM, Vasilopoulos K, Yoshida S, Kaye AH, Chow CW and Gonzales MF: Overexpression of multiple oncogenes related to histological grade of astrocytic glioma. Br J Cancer 66: 106-112, 1992.

21. Zhu R, Kang S and Wu D: Expression of p53, c-erbB1, c-myc and p16 gene proteins in human glioma. Zhonghua Bing Li Xue Za Zhi 26: 343-345, 1997 (In Chinese).

22. Zheng X, Yao Y, Xu Q, Tu K and Liu Q: Evaluation of glioma-associated oncogene 1 expression and its correlation with the expression of sonic hedgehog, E-cadherin and S100a4 in human hepatocellular carcinoma. Mol Med Rep 3: 965-970, 2010.

23. Ohta M, Tateishi K, Kanai F, Watabe H, Kondo S, Guleng B, Tanaka Y, Asaoka Y, Jazag A, Imamura J, et al: p53-Independent negative regulation of $\mathrm{p} 21 /$ cyclin-dependent kinase-interacting protein 1 by the sonic hedgehog-glioma-associated oncogene 1 pathway in gastric carcinoma cells. Cancer Res 65: 10822-10829, 2005.

24. Godlewski J, Nowicki MO, Bronisz A, Williams S, Otsuki A, Nuovo G, Raychaudhury A, Newton HB, Chiocca EA and Lawler S: Targeting of the Bmi-1 oncogene/stem cell renewal factor by microRNA-128 inhibits glioma proliferation and self-renewal. Cancer Res 68: 9125-9130, 2008. 